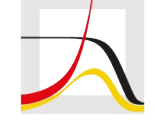

MAX PLANCK INSTITUTE

FOR DEMOGRAPHIC RESEARCH

Konrad-Zuse-Strasse 1 · D-18057 Rostock · Germany · Tel +49 (0) 3812081 - $0 \cdot$ Fax +49 (0) 3812081 - $202 \cdot$ www.demogr.mpg.de

MPIDR Working Paper WP 2021-011 I June 2021

https://doi.org/10.4054/MPIDR-WP-2021-011

\title{
Forecasting of Cohort Fertility by \\ Educational Level in Countries with \\ Limited Data Availability: The Case of \\ Brazil
}

Ewa Batyra I batyra@demogr.mpg.de

Tiziana Leone

Mikko Myrskylä I sekmyrskyla@demogr.mpg.de

(c) Copyright is held by the authors.

Working papers of the Max Planck Institute for Demographic Research receive only limited review. Views or opinions expressed in working papers are attributable to the authors and do not necessarily reflect those of the Institute. 


\title{
Forecasting of Cohort Fertility by Educational Level in Countries with Limited Data Availability: The Case of Brazil
}

\author{
Ewa Batyra ${ }^{\mathrm{a}}$, Tiziana Leone ${ }^{\mathrm{b}}$, Mikko Myrskyläa,b,c \\ a-Max Planck Institute for Demographic Research, Germany. \\ $b$ - London School of Economics and Political Science, UK. \\ $c$ - University of Helsinki, Finland
}

\begin{abstract}
The Brazilian period fertility rate (PTFR) dropped from six to 1.8 between 1950 and 2010. Due to the shifts in the timing of fertility, the PTFR might be providing a misleading picture of fertility levels. Moreover, the national average hides important educational differences, as in 2010, the PTFR was 2.3 among the lower educated, whereas it had fallen to 1.5 among the higher educated. The consequences of these changes for the cohort total fertility rate (CTFR) - a measure that is free from tempo distortions - and for the educational differences in completed fertility have not been previously studied. Due to the scarcity of time series of fertility rates, the application of CTFR forecasting methods outside of high-income countries (HICs) has been rare, and has been largely limited to population-level analysis. We use four Brazilian censuses to forecast the CTFR for the total population and by educational level using rates reconstructed with indirect techniques. The results of four forecasting methods indicate that the CTFR is likely to decline to 2.1 for the 1980 cohort, and to 1.9 for the 1984 cohort. Educational differences in the CTFR are likely to remain stark - at between 0.7 and 0.9 depending on the cohort and the method - and to be larger than they are in HICs with comparable CTFRs. We show how the CTFR can be forecasted, including by educational level, in settings with limited data. Finally, we call for more research on the educational differences in completed fertility in low- and middle-income countries.
\end{abstract}

Keywords: cohort fertility, forecasting, Brazil, education, census data 


\section{Introduction}

From the 1950s to 2010, the period total fertility rate (PTFR) in Brazil plummeted from above six to 1.76 (Castanheira and Kohler 2016). As a result of this sharp decline, Brazil became the first out of all countries in Latin America that have experienced rapid fertility declines since the 1950s to reach low fertility levels (Chackiel and Schkolnik 1996). This development has led to concerns being raised about the potential implications of Brazil's below-replacement fertility for the country's population age structure, and for the sustainability of its intergenerational relations (Goldani 2002; Castanheira and Kohler 2016).

It is well known that period fertility measures can be subject to fluctuations due to changes in fertility timing; the so-called tempo effects (Bongaarts and Feeney 1998). If women are advancing or postponing motherhood, the PTFR can be inflated or depressed, even if the number of children women have over their lifespan is not changing. In many European and East Asian countries, parenthood postponement was one of the drivers of very low period fertility levels during the 1990s, and of the subsequent rebounds in the PTFR during the 2000s (Goldstein et al. 2009; Kohler et al. 2002). Due to the shifts towards later childbearing, the cohort fertility indicators in these settings have been higher than the period fertility indicators (Myrskylä et al. 2013). This is because cohort fertility is a measure of the average number of children women have during their lifetime, and is free from the impact of the tempo distortions. Consequently, a growing number of studies have focused on examining and forecasting cohort fertility in order to provide a more comprehensive picture of changes in fertility levels. However, the detailed studies on cohort fertility have mainly focused on high-income countries (HICs), such as Finland and other Nordic settings (Hellstrand, Nisén, Miranda, et al. 2020; Hellstrand, Nisén, and Myrskylä 2020).

While the future of fertility in low- and middle-income countries (LMICs) where fertility has declined rapidly, such as in Brazil (Goldani 2002), is being increasingly debated, the research on fertility in these countries has thus far been dominated by studies of PTFR, and there have been few attempts to study and forecast cohort fertility. However, given the recent changes in the timing of motherhood, taking the limitations of period fertility measures into account is becoming increasingly important. Starting in the 2000s in Brazil, a reversal of previously pervasive increases in teenage fertility occurred, and women started to postpone motherhood (Rosero-Bixby et al. 2009; Rios-Neto et al. 2018). Currently, we have only a limited understanding of whether the continued declines in period fertility measures that have 
been observed in Brazil will translate into decreases in the average number of children women have throughout their lifetime.

Moreover, one of the most notable features of the fertility patterns in LMICs, including those in Latin America, is that there are large disparities in reproductive behaviour by educational level. Because social and economic inequality levels are high in Brazil, it has been argued that different population strata in the country are at distinct stages of fertility transition (Miranda-Ribeiro and Garcia 2013). The stark polarisation of reproductive behaviour has been reflected in the uneven changes in the PTFR, which has been below the replacement level since the 1990s among women who entered secondary school, but was above two children per woman in 2010 among those with less than secondary school (Berquó and Cavenaghi 2014; 2005; Cavenaghi and Berquó 2014). Examinations of cohort fertility in HICs have shown that in these countries, there have been important shifts in the associations between education, the timing of childbearing, and fertility levels; as well as substantial variation in completed fertility by educational level between and within countries (e.g., Berrington et al. 2015; Yoo 2014; Nisén et al. 2021; Jalovaara et al. 2019). Moreover, focusing on European countries, Nisén et al. (2021) suggested that settings characterised by lower levels of development tend to have larger differences in completed fertility by educational level. While it is clear that there are pronounced disparities in reproductive behaviour by socio-economic status in LMICs, there has been little research on educational differences in completed fertility; and specifically in Brazil, there has been only one study on this topic (Rios-Neto et al. 2018). Moreover, no previous study has attempted to forecast cohort fertility disaggregated by educational level in LMICs with low fertility. Thus, performing such an analysis could enhance our knowledge about the relationship between the level of a country's development and the educational gradient in completed fertility.

The aim of this study is to make a novel contribution by forecasting cohort fertility for the total population and by educational level in Brazil. In doing so, we address one of the main barriers to cohort fertility forecasting in LMICs: namely, a scarcity of published estimates of fertility rates disaggregated by single groups of age and year, which are among the inputs necessary for such forecasts. The forecasting of fertility by educational level is particularly challenging because there are no fertility data series disaggregated by measures of education. In this study, we use data from four rounds of censuses conducted between 1980 and 2010 that are available through International Public Use Microdata Series (IPMUS) and indirect estimation techniques to reconstruct long-term series of detailed fertility rates, both for the total 
population and by educational level. To the best of our knowledge, there have been no previous attempts to examine the potential of using IPUMS data for the estimation of long-term time series of fertility rates disaggregated by single age and year.

In the following, we forecast completed fertility, including by educational level, for women born between 1966 and 1985 using four methods: a simple freeze rate method, a method based on the five-year extrapolation of the age-specific fertility rates (Myrskylä et al. 2013), a Bayesian model developed by Schmertmann et al. (2014), and a Bayesian model proposed by Ellison et al. (2020). Previous large-scale evaluations of forecast accuracy have shown that the naïve freeze rate method outperforms most other forecasting approaches, and that the limited extrapolation method developed by Myrskylä et al. (2013) and the method proposed by Schmertmann et al. (2014) are among the best-performing methods (Bohk-Ewald et al. 2018). We also apply the Bayesian method put forward by Ellison et al. (2020). This method is the most recent forecasting approach proposed in the literature, and the authors claim that it performs as well as the other three methods. We present the results obtained from the four forecasting approaches, which allows us to provide the most comprehensive examination to date of future cohort fertility developments in a middle-income country with low fertility, including for subpopulations according to educational level.

\section{Fertility and Timing of Childbearing in Brazil}

The rapid decline in the PTFR since the 1950s in Brazil has been attributed to a number of factors, including social and economic transformations, modernisation, urbanisation, and women's labour market participation (Carvalho and Rodríguez Wong 1996; Martine 1996); changes in values and attitudes due to, among other factors, the spread of mass communication and TV, including the popularity of soap operas (Ferrara et al. 2012; Rios-Neto et al. 1998); and the specificity of the contraceptive method mix in Brazil, with "limiting" methods such as sterilisation being the main method of birth control (Potter 1999; Leone 2002; Caetano and Potter 2004).

Brazil provides clear evidence of the validity of the ideational theory of fertility decline, as the shift in fertility was observed first among the most privileged, urban social groups of the most developed parts of the country. Since the 1970s, the fertility decline has spread across the whole population (Carvalho and Rodríguez Wong 1996). The PTFRs have been falling among 
all social classes, in both urban and rural areas, and across all of the states, with the highest socio-economic strata leading the trend. Nevertheless, differences in reproductive behaviour between the population groups have persisted. By the 1990s, the PTFR had already fallen below the replacement level among women who entered secondary school, and among women with higher earnings. Among women who had not attended secondary school or who had lower household income levels, the period fertility rate remained above two in 2010 (Berquó and Cavenaghi 2014; 2005; Cavenaghi and Berquó 2014). Thus, in Brazil, the educational differences in fertility levels remain large.

During the 1990s, the uninterrupted decline in fertility in Brazil took place in the context of increases in teenage fertility and decreases in the average age at first birth. The trend towards earlier motherhood was observed among all population groups, but it was most prominent among women who had lower levels of schooling and belonged to poorer population groups (Rodríguez Vignoli 2013; Martins 2016). This development highlights the role of education in shaping not only fertility levels, but also fertility timing. Although there is no clear-cut explanation for this unique phenomenon, the reasons for the rejuvenation of the fertility pattern in Brazil and Latin America more broadly have been extensively discussed in the literature. While some studies have suggested factors such as limited access to contraception and increasing levels of unintended childbearing, other researchers have pointed to the effects of poverty, limited social mobility, and the low opportunity costs of early motherhood (Azevedo et al. 2012; L. Marteleto and Dondero 2013; Rodríguez Vignoli 2014; 2017).

A number of studies have shown that the trend towards earlier motherhood reversed during the 2000s. Teenage fertility decreased for the first time in Brazil between 2000 and 2010 (Verona 2018). According to Miranda-Ribeiro and Garcia (2013), after a steady decline starting in the 1980s, the mean age of childbearing and the mean age at first birth increased between 2000 and 2010 in Brazil. The onset of the postponement transition in Brazil has been discussed in Rios-Neto, Miranda-Ribeiro, and Miranda-Ribeiro (2018). This study and other research on the topic has suggested that the "retreat from early childbearing" has been most pronounced among more educated women (Lima et al. 2018; Rosero-Bixby et al. 2009). Thus, in order to understand the course of fertility change in these settings, it is becoming increasingly necessary to go beyond a reliance on fertility measures that are prone to tempo distortions, and to take into account the variation in fertility behaviour by socio-economic status. 


\section{Impact of Changes in the Timing of Fertility on Period Fertility and Cohort Fertility in Brazil}

Previous attempts to examine the effects of the changes in the timing of childbearing on fertility levels in Brazil have focused on applying TFR tempo adjustment methods (Miranda-Ribeiro et al. 2008; Rios-Neto and Miranda-Ribeiro 2015). These studies suggested that changes in the timing of childbearing were responsible first for an inflating (negative) TFR tempo effect between the late 1980s and the 2000s, and, subsequently, a deflating (positive) TFR tempo effect between the second half of the 2000s and 2010. A well-known limitation of the tempoadjusted TFR is that it is a synthetic indicator, and thus does not allow for the examination of the possible levels of fertility of real cohorts of women. By contrast, cohort fertility measures correspond to the actual fertility experiences of women. Thus, these measures can be used to examine whether women are having more or fewer children over their lifespan, and the interpretation of these measures is straightforward.

Two previous studies have examined the future of cohort fertility in Brazil, and both consistently showed that the cohort total fertility rate (CTFR) decreased among women born between 1950 and 1965, from around 3.5 to 2.5 (Miranda-Ribeiro et al. 2017; Schmertmann et al. 2014). The Bayesian forecast of Schmertmann et al. (2014) suggested that the CFR for women born between 1975 and 1985 was likely to plateau, and could range between two and 2.5 children per woman. These results are different from the forecast of Miranda-Ribeiro, Miranda-Ribeiro, and Rios-Neto (2017). Using ARIMA models, their findings suggested that the CTFR could continue to decrease, declining to around 1.7 for women born in 1980. Thus, our knowledge about the future cohort fertility developments in Brazil is still limited. Moreover, forecasts of cohort fertility by level of education are lacking, which leaves a gap in our understanding of the plausible course of educational differentials in cohort fertility. Such forecasts are important, given that the differences in completed fertility by educational level among women born in 1970 appear to be substantial: at age 40, the number of children ever born to women of this cohort was 1.7 for those who had more than eight years of schooling, three for those with 0-3 years of schooling, and 2.4 for those with 4-8 years of schooling (RiosNeto et al. 2018). 


\section{Data}

This study uses microdata from the Brazilian Population and Housing Censuses conducted in 1980, 1991, 2000, and 2010. These data come from the International Public Use Microdata Series (IPUMS) (Minnesota Population Center 2017). The IPUMS provides harmonised census samples, which are well-suited for the analysis of demographic phenomena over time. We reconstruct the time series of period age-specific fertility rates (ASFRs) by single age and year, as well as by the level of education. The rates are calculated for women of reproductive age (15-49) for the years 1966-2010 using the information about women aged 15-64 from each of the censuses. The details about the census samples used in this study are in Table 1.

\section{[Tab. 1]}

We estimate the time series of ASFRs using the own children method (OCM) (Cho et al. 1986). The OCM is an indirect technique that can be applied to estimate fertility rates in settings where vital registration data or birth histories from surveys are not available. While this method has been previously used to reconstruct trends in age-specific fertility rates in Brazil (Lima 2013), the rates have been aggregated into five-year age groups. The fertility forecasting methods we use here require age-specific fertility rates disaggregated by single age and year. Although aggregated rates can be split into more granular estimates using smoothing or interpolation techniques, in this paper, we use the OCM to estimate the rates directly into single age and year groups, and use the raw data for the analysis. We prefer this approach for two reasons. First, no additional data manipulation, such as smoothing or interpolation, is necessary. This enables us to avoid the risk that the data might be over-adjusted or oversmoothed due to the initial grouping and subsequent disaggregation of the rates. The question of how this kind of data manipulation influences fertility trends cannot be answered if the disaggregated estimates are not available. Second, this approach allows us to assess the quality of the raw, single-age group estimates, which we do and then discuss in the next paragraphs. Below, we describe the input data that are needed to reconstruct fertility trends using the OCM for Brazil. The analysis is performed in two stages.

First, this method involves matching the enumerated children (aged 0-14) in the census to their mothers (women aged 15-64), if they live in the same household. The method allows for the estimation of the fertility trends for the period of 15 years prior to the census for women 
aged 15-49. It is conventionally assumed that a large percentage of children will be living in the same household as their mother up to age 15 (Cho et al. 1986). The IPUMS data are wellsuited for the OCM estimation because they include the Constructed Family Interrelationship module. We use two variables that together allow us to easily identify biological mothers and stepmothers of children: (i) "momloc" (mother's location in the household) and (ii) "stepmom" (probable stepmother). The matched children ("own" children) are then classified according to their age and the age of their mother in order to generate a mother-child matrix. This matrix also includes the number of children who were not matched to any women ("not-own" children), by their age.

Second, the "non-own" children of a given age are redistributed proportionally among women according to the distribution of the "own" children by age of women. We make adjustments for under-enumeration in the census based on the information published by the Brazilian Statistical Office (IBGE 2008). Next, both children and mothers are reverse-survived to estimate two quantities for each of the 15 years prior to the census: (i) the number of births by women's age and (ii) the number of women by age. For the reverse-survival, we use the information about life expectancy at birth for each year between 1966 and 2010 published by the World Bank (World Bank 2020). These estimates are based on the estimates of the United Nations Population Division, and are annual data interpolated from five-year period data. We compare these estimates with those published by the Brazilian Statistical Office for periods for which estimates are available (IBGE 2010b). The estimates from the two sources are consistent. To obtain a mortality pattern from the information on life expectancy at birth for each year preceding the census, we use the "West" Coale-Demeny model life table (UNDESA 1982). Finally, the age-specific fertility rates for each year are calculated by dividing the number of reverse-survived births by the number of reverse-survived women. For these analyses, we use a programme written by Lwendo and Levin (2017).

The OCM has several key limitations (Retherford et al. 1979; Cho et al. 1986; Brass 1975). Trends in fertility estimated using the OCM may be distorted by women's or children's age misreporting. Estimates may be biased by migration, and by the fact that the fertility of surviving women may be different from the fertility of deceased women. One of the ways to assess the existence of such biases is to compare overlapping retrospective estimates from two censuses (Cho et al. 1986). Since censuses in Brazil were conducted every 10 years, it is possible to compare the estimates from two census rounds for a five-year period. If the data are affected by age misreporting or other sources of bias, the trends between the censuses will 
overlap poorly. However, we find that the agreement between the rates from each of the two pairs of censuses is very good (Fig. 1, left). This check gives us confidence that the age-specific trends do not have systematic inconsistencies that could affect the results of the further analysis. For the years for which overlapping estimates exist, we combine them as follows. We sum the number of the reverse-survived births to women aged $x$ in year $t$ from two censuses, and divide them by the sum of the number of reverse-survived women aged $x$ exposed to the risk of birth in year $t$ from two censuses (Fig. 1, right). A similar approach has been previously used to combine overlapping estimates from surveys (Cetorelli 2014).

\section{[Fig.1]}

While the procedure for reconstructing the ASFRs by educational level using the OCM is the same as for the total population, two additional aspects need to be considered when education is included. First, when fertility trends are estimated by socio-economic characteristics, the OCM method is based on the assumption that a value of a given characteristic at the time of the census applies to the time period for which the rates are reconstructed (Rindfuss and Sweet 1977). Thus, this method should be used with caution when disaggregating trends by characteristics that might change over time. In the case of education, women might progress to higher educational levels after the beginning of the reproductive period. For that reason, we group women into two educational groups that are not very likely to change after the age of 15 , but that still provide an informative distinction between women with lower and higher levels of schooling. The first group is made up of women who had no education or completed primary school only (up to eight years of schooling), while the second group consists of women who completed at least the first year of secondary school (9+ years of schooling). Throughout this study, these groups are referred to as the low and the high educational groups, respectively. The rationale for this division is that in Brazil, students start primary school at the age of seven and graduate at the age of 15 . This classification aims to minimise the problem of the subsequent progression to higher educational levels among the youngest women. This means that we are unable to disaggregate the trends by more detailed educational groups; for example, for women who entered university. However, this division is very relevant for examining the changes in the PTFR and the CTFR in Brazil. As we noted in the previous sections, the PTFR remains above the replacement level among women with less than secondary education, but it has been below the replacement level among women who 
completed some secondary school since the 1990s. Further details regarding the estimation of the ASFRs by educational level are described in the Online appendices (Appendix 1).

Second, for the period covered by this analysis, the detailed life tables or estimates of life expectancy at birth are not available for Brazil for educational groups. We assumed that the mortality pattern is the same among all individuals. We conducted a sensitivity analysis to examine how the results would change if differentiated patterns of mortality between educational groups were assumed (see Online appendices, Appendix 2). The differences in the reconstructed trends in fertility are small, and the main conclusions of this study remain unchanged. These findings are consistent with analyses that showed that the OCM is not sensitive to mortality assumptions (Retherford et al. 1980; Cho et al. 1986; Scalone and Dribe 2017).

Overall, the PTFR estimates obtained based on the reconstructed ASFRs align with the existing estimates of the PTFR for each of the census years for the total population (IBGE 2010a) and for women with 9+ years of schooling (Rios-Neto et al. 2018). ${ }^{1}$

\section{Methods}

We use the estimated time series of ASFRs for the years 1966-2010 to calculate the PTFRs. Combining the trends in the period age-specific rates from four censuses from 1966 to 2010 allows for the reconstruction of the entire age-specific fertility schedules and the CTFRs of women born between 1951 and 1966. We consider the fertility experience of a cohort to be complete at the age of 44, since few births occur beyond that age (Frejka and Sardon 2004). ${ }^{2}$ For women born after 1966, the full fertility schedules are unknown, and we forecast the ASFRs and CTFRs for these cohorts using approaches described below. Fertility forecasts are usually limited to women who were 30 years old at the time of the forecast (Hellstrand, Nisén, and Myrskylä 2020; Myrskylä et al. 2013; Hellstrand, Nisén, Miranda, et al. 2020) because forecast uncertainty, and the risk of forecast error, increases for younger women. Consequently, while we show the CTFR forecasts for women born up to 1984 (26 years old at the forecast

\footnotetext{
${ }^{1}$ We did not identify studies that estimated the PTFR for women with 0-9 years of schooling. Usually, the rates are estimated for more detailed educational categories (e.g., 0-3 and 4-8 years), which does not allow us to conduct direct comparisons with existing estimates.

${ }^{2}$ Since in this study we consider the age of 44 to mark the end of the reproductive life in the cohort analysis, for consistency, the TFR is also calculated for the 15-44 age group.
} 
year), we mainly discuss forecasts for women born up to 1980 (30 years old at the forecast year) due to the high degree of incertainty inherent in forecasting the fertility of younger women.

We apply four forecasting methods: a simple freeze rate method, a method based on the five-year extrapolation of the age-specific fertility rates (Myrskylä et al. 2013), a Bayesian model developed by Schmertmann et al. (2014), and a Bayesian model proposed Ellison et al. (2020). All of these methods require age-specific fertlity rates by single age and year, but are based on different assumptions. The simple freeze rate method assumes that the most recent age-specific fertility rates will ramain constant for subsequent cohorts. It involves freezing a given age-specific rate at the last observed value, and assuming that the fertility rates at a given age for cohorts with incompleted schedules will be the same as those for the last cohort with the observed fertility rate. The method based on the five-year extrapolation assumes that the recent trends in the age-specific fertlity rates will continue into the future. This method involves estimating the trend based on the past five years, extrapolating it five years into the future, and then freezing the rates (Myrskylä et al. 2013).

The two Bayesian models produce probabilistic forecasts. The advantage of these models is that they provide estimates of uncertainty. The model of Schmertmann et al. (2014) incorporates information about the historical age patterns in cohort fertility and the trends in age-specific fertlity rates. These historical data are used as a source of prior information about changes in cohort fertlity schedules (shape prior) and in fertility rates at each age (time series prior that balances two extrapolation techniques: the freeze rate and the freeze slope). These priors are combined to identify fertility surfaces that are plausible or implausible, given the fertility patterns observed in the historical data. Although this model originally uses both shape and time series priors, it can also be applied using the time series prior only. This approach may be preferable when the cohort fertility schedule of interest is not well-represented in the historical data (Hellstrand, Nisén, and Myrskylä 2020). Our application suggests that this is the case for Brazil, as the model with the shape prior imposes a heavy penalty on the Brazilian cohort age pattern. This is likely because the historical data, which are the source of prior information about the plausible cohort fertility schedules, do not include examples of age profiles of fertility similar to that of Brazil, as they are based on data from the US and from countries in Europe and Asia only. Consequently, we implement this Bayesian model while only incorporating the time series priors. 
The Bayesian model of Ellison et al. (2020) is built on an idea similar to that of Schmertmann et al. (2014). It is also based on prior information from historical data, but it does not build the shape prior into the model. It incorporates the assumptions about the time series trends only - also by balancing the freeze rate and the freeze slope approaches - and, among other differences, applies them to the error terms of the model rather than to actual rates, as in the case of the model of Schmertmann et al. (2014). When describing the results, we refer to this model as "Bayesian 2020", and we refer to the model of Schmertmann et al. (2014) as "Bayesian 2014".

We chose these four methods based on a recent evaluation of forecast performance across a large number of countries (Bohk-Ewald et al. 2018). This evaluation suggested that only a few methods out of the 20 considered perform better than the simple freeze rate method. The five-year extrapolation tends to outperform other methods in terms of forecast accuracy. The limitation of this approach is that it does not perform well in the quantification of uncertainty, whereas the two Bayesian model have been shown to provide more accurate uncertainty estimates. Thus, there is a benefit to producing forecasts using all four methods, and we show the CTFR forecasts based on all of them. We use the same methods to forecast cohort fertility by educational level. For the Bayesian approaches, we include data for the total population and the educational subgroups as separate "national" populations within the same model. In order to implement the methods, we use STATA code provided by Myrskylä et al. (2013), and slightly modified R codes provided by Schmertmann et al. (2014) and Ellison et al. (2020).

\section{Results}

Figure 2 shows recent PTFR and CTFR trends for the total population. The CTFR is observed for women born in 1964-1965, and is forecasted for those born after 1966. The PTFR prior to 1990 and the observed CTFR for women born before 1964 are presented in the Online appendices (Appendix 3). In order to plot the period and cohort measures together, we lag the CTFR by the mean age of childbearing of the last cohort with completed fertility experience (26 years). ${ }^{3}$

\footnotetext{
${ }^{3}$ The results would be very similar if lagged by any value of MAC from the range observed for the cohorts born between 1951 and 1984.
} 
According to the reconstructed trend, the PTFR declined to 1.79 in 2010. The CTFR of the cohort born in 1965 was around 2.5, which corroborates findings from previous studies (Schmertmann et al. 2014; Miranda-Ribeiro et al. 2017). According to all four forecasts, lifetime fertility is likely to continue declining for women born after 1966, and to reach around 2.3 children per woman for those born in 1975 . For the 1980 cohort, the CTFR is likely to remain close to 2.1 children per woman. The $95 \%$ probability intervals from the 2014 and 2020 Bayesian models suggest that its value could range from around 2.1 to 2.2. While further declines are likely, the uncertainty around the estimates increases markedly for younger women. For example, for women born in 1985, the mean of the CTFR forecast is 1.9, with confidence intervals indicating that it could range from 1.8 to 2.1. As expected, the freeze rate method produces the lowest CTFR of all the methods, because it assumes that the fertility rates at a given age for subsequent cohorts will remain the same. Nonetheless, all four methods point to the same future trend. Overall, the forecasts suggest that for women born in the 1980s, the CTFR is likely to remain around the replacement level, and above the PTFR value of around 1.79 observed in 2010 .

$$
\begin{aligned}
& \text { [Fig.2] } \\
& \text { [Fig. 3] }
\end{aligned}
$$

The decrease in the PTFR between 2000 and 2010 in Brazil - as shown in Figure 2 - was driven by a decline in fertility rates below age 25 , and by a decline in teenage fertility in particular (Verona 2018; Berquó and Cavenaghi 2014). Since these changes correspond to shifts in the behaviour of women who are not covered by our forecast, we are unable to speculate about what the completed fertility of these cohorts could be. Instead, we can explore the likely evolution of the cohort ASFRs for women born up to the 1980s, which provides insights into the emerging shifts in the timing of childbearing across cohorts in Brazil. Figure 3 (left panel) shows the age-specific fertility profiles of three cohorts: 1960, 1970, and 1980 (forecasts from 2014 Bayesian model). The fertility schedule of women born in 1960 is complete, and is presented as a solid line. The solid lines for women born in 1970 and 1980 represent observed rates; while the forecasts are shown as dashed (mean of the CTFR forecast) and dotted (95\% CIs) lines. These schedules show a drastic change in the age profile of fertility driven by a general fertility decline, which is reflected in large reductions in fertility above age 20 between the 1960 and 1970 cohorts. The subsequent declines in fertility observed for the 1980 cohort were concentrated between ages 20 and 30. The mean of the CTFR forecast 
(dashed line) for this cohort suggests that the decline in fertility rates above age 30 observed among the older cohorts is likely to halt, and there might be even very subtle increases in the rates of this cohort compared to those of the 1970 cohort. This implies that the pattern of the timing of fertility may be shifting, with the rates at older ages no longer declining. The advantage of using a Bayesian model is that it allows us to highlight the uncertainty inherent in the forecast, as shown by the $95 \%$ CIs (dotted lines).

[Fig.4]

Figure 4 shows that the education-specific fertility trends are very different, and that the analysis of the total population conceals important differences in fertility behaviour between educational groups. Among the lower educated women, the PTFR declined rapidly between 1990 and 2000s, to 2.3 children per woman on average in 2007. While the CTFR trend is likely to be more stable, it also points to a plausible continuation of the fertility decline from around three to around 2.7 children per woman on average between the 1966 and the 1975 cohorts. For women born after 1975, the forecasts from the four methods start to diverge slightly. While the freeze rate and the Bayesian forecasts are very close together, the five-year extrapolation method suggests that there is likely to be a more pronounced decline. Nonetheless, the estimate from the latter method is within the 95\% confidence interval of the 2014 Bayesian model (but not the 2020 model). Overall, all of the methods suggest that the cohort fertility decline among the lower educated women is plausible, but that there is a high probability that the CTFR will remain above two children per woman on average for those born during the 1980s.

Conversely, among women with the higher level of schooling, the PTFR was already below the replacement level in 1990, and continued to decline to around 1.5 in 2010. Similarly, the CTFR for the 1964 cohort was around 1.9, and is forecasted to continue declining to around 1.65 among women born in 1975. As we observed for the lower educated women, the mean estimates of the Bayesian models and the freeze rate method for the higher educated women born after 1975 are more similar than those suggested by the five-year extrapolation method. Nonetheless, the differences between the forecasts are not large, and all of the mean estimates are within the $95 \%$ CIs of both Bayesian models. All four methods suggest that there is likely to be a plateauing of the CTFR for women born between the 1975 and 1980, or even a plausible reversal of the decline, according to the five-year extrapolation method. The $95 \% \mathrm{CI}$ indicate that for women with higher education born in the 1980s, the CTFR could range from 1.6 to 1.7. 
The changes in the cohort fertility schedules, both observed and forecasted, cast further light on the stark differences in the fertility patterns of the educational groups (Fig. 3, middle and right panels). Among the lower educated, the cohort schedule shifted to the left due to the substantial decreases in fertility above age 20 and the subsequent increases in fertility below age 20. The forecasted declines in the CTFR among the lower educated women born in 1980 shown in Figure 4 are the result of the observed reductions in fertility between ages 20 and 30, and according to the mean of the CTFR forecast (dashed line), the rates are likely to continue to decline between ages 30 and 35. Conversely, the fertility decline among the higher educated women was concentrated between ages 20 and 30. As was observed among the lower educated women, teenage fertility increased for higher educated women born in 1980, which was not unexpected. As we explained in the data section, the highly educated group in this study includes women who entered secondary school. Although the increase in teenage fertility was most pronounced among women with the lowest levels of schooling, it was observed among the secondary school entrants as well (Rodríguez Vignoli 2013; Martins 2016). The mean of the CTFR forecast (dashed line) suggests that fertility rates above age 30 are likely to be higher for the 1980 cohort than for the 1970 cohort. Thus, the pronounced decreases in fertility observed among some members of the 1980 cohort during their twenties are likely to be recuperated at older ages. These results suggest that there is a plausible and important shift in the pattern of fertility at older ages among women with more advanced levels of schooling.

In order to examine the likely developments of educational differences in CTFRs in greater depth, Table 2 shows gaps in completed fertility calculated based on the observed (1960 and 1964 cohort) and forecasted (1970-1984 cohorts) CTFRs by educational level. Educational differences in completed fertility declined from around 1.4 children per woman on average for the 1960 cohort to around 1.15 for the 1964 cohort. According to all the forecasts, this downward trend is likely to continue. Nonetheless, even for the youngest cohorts born in the early 1980s, for whom the forecasted CTFRs are close to the replacement level, the educational differences in completed fertility are likely to remain substantial. They could range from 0.73 to 0.94 children per woman on average, depending on the method and cohort.

[Tab. 2]

Although comparisons are difficult due to differences in how educational levels have been classified across studies, the forecasted educational differences in completed fertility in Brazil 
appear to be larger than those documented in other settings with comparable cohort fertility levels. In South Korea, the decline of the CTFR to the replacement level coincided with a convergence of fertility between the educational groups (Yoo 2014). In the Nordic countries, as the CTFR declined from around 2.1-2.3 to 1.9 (Denmark, Norway) or remained constant at around 1.9 (Finland, Sweden), educational differences in completed fertility between the lowest and the highest educated remained at around 0.3 children per in Finland, and disappeared in Denmark, Norway, and Sweden (Jalovaara et al. 2019). A study of 15 European countries suggested that for countries where the CTFR was between 1.9 and 2.1, the educational differences ranged from 0.03 (Norway, CTFR of two) to 0.69 in Hungary (CTFR of 1.86). Finally, according to a study conducted in the UK, for cohorts for whom the CTFR was around two children per women, the difference in the completed fertility of the lowest and the highest educated women was 0.67 (Berrington et al. 2015). Consequently, our forecasts indicate that the educational differences in Brazil are likely to be larger than the differences previously documented in other settings with comparable CTFR levels. It should be noted that our estimates of the differences for Brazil constitute a conservative scenario because in our study, higher education is defined as secondary school attendance. In the studies highlighted above, higher education pertained to tertiary education. It is possible that if we were able to estimate completed fertility for women in tertiary education, the educational differences between the lower and the higher educated in Brazil would be even larger.

\section{Conclusions}

This is the first study for Brazil, and for Latin America more broadly, to provide a comprehensive picture of the plausible future developments in cohort fertility, including for subpopulations according to educational level. Unlike the period fertility rate, the cohort fertility rate is a measure that is free from the impact of tempo distortions, and can be used to estimate how many children, on average, women have over their lifespan. The range of methods that we used, which include indirect methods of fertility reconstruction and probabilistic forecasting approaches, allowed us to cast light on the likely future cohort fertility trajectory, as well as on the uncertainty around the forecasted rates. This research has several implications for the study and the measurement of fertility in Brazil, Latin America, and LMICs more broadly. 
First, we showed that the Brazilian fertility pattern is undergoing substantial shifts related to the timing of childbearing and completed fertility, which vary between educational groups. Although cohort fertility is forecasted to continue declining at the population level, our results suggest that the long-observed declines in fertility rates above the age of 30 are likely to stop among the younger cohorts. Among the higher educated women, we documented plausible increases in fertility rates above the age of 30 , and a halt, or even a reversal, of declines in completed fertility. These processes reflect the postponement of fertility among some members of that subpopulation, which is likely to result in the fertility reductions observed among women in their twenties being recovered later in life. These results suggest that the longstanding early childbearing pattern in Brazil has weakened, which is likely to translate into novel changes in fertility rates at older ages among the younger cohorts. In addition, these results lead us to conclude that in the future, the period fertility measures are likely to increasingly underestimate the "true" fertility levels, and will thus provide only a limited picture of changes in fertility levels. This might be particularly the case in the coming years, given the large declines in fertility among women under age 25 that have been observed since 2000s (Verona 2018; Berquó and Cavenaghi 2014), and, most recently, the plausible impacts of the Zika and Covid-19 epidemics, and the associated crises, on women's fertility intentions (Marteleto et al. 2021). The forecasting of cohort fertility when these women reach their thirties will be needed to assess the impact on fertility levels of the ongoing changes in the timing of childbearing. Thus, in the future, more attention should be paid to studying and forecasting cohort fertility in Brazil and other Latin American countries that have experienced similar changes in fertility timing.

This study provides a description of the process for estimating the time series of agespecific fertility rates, and the cohort fertility analysis can be easily replicated for the upcoming censuses and other Latin American countries. The countries in the region have a long history of census data collection. The samples of the majority of these censuses have been harmonised, and are available through the IPUMS, which is also the case for many other LMICs. By contrast, access to full census data is often more restricted. Another advantage of the IPUMS data for the estimation of the time series of fertility rates using the OCM is the availability of the constructed family interrelationship variables, which greatly facilitates the analysis. One of the largest barriers to studying and forecasting cohort fertility in LMICs is the lack of necessary input data. This study showed that using the IPUMS censuses, it is possible to indirectly estimate detailed trends in fertility rates by single year and age, at least for Brazil. While the 
internal consistency of the ASFRs does not guarantee their accuracy, it assures us that the trends are not systematically distorted by the kinds of problems that often arise in fertility estimates in LMICs. Given the scarcity of published time series of fertility rates in settings like Latin America, such fertility reconstruction techniques provide a promising alternative.

Another novelty of this study was that we applied the abovementioned fertility reconstruction and forecasting techniques to study educational differences in completed fertility. This is important, because in the Latin American context, the analysis of the total population can conceal large differences in fertility between population strata. The results showed that while educational differences in completed fertility are likely to continue to decline, they are unlikely to disappear for the youngest cohorts. Indeed, our forecasts suggest that these differences could continue to remain large. Although the cohort fertility of higher educated women is likely to plateau, and we can expect to observe increases in fertility rates above age 30, completed fertility is forecasted to remain at below replacement level (around 1.6-1.7 for women born after 1975). It is evident that large shares of educated women in Brazil are stopping having children after the birth of the first child. This could mean that women who transition to motherhood later in life might not have enough time to "catch up", or do not want to continue childbearing after having one child. To shed more light on these processes, future research should focus on exploring the determinants of cohort fertility in Brazil and Latin America more broadly. While an increasing body of literature has investigated the socioeconomic disparities in the timing of childbearing in the region, there is scarcity of studies examining the determinants of socio-economic differences in completed fertility.

Research on fertility Europe has suggested that there is a relationship between economic development and the educational gradient in completed fertility, and that this gradient is steeper in less developed settings (Nisén et al. 2021). Our study has shown that the educational gaps in Brazil could be larger than those observed in HICs with similar CTFRs. This finding highlights the importance of extending research on the topic to LMICs characterised by low fertility, and of conducting comparative analyses between settings at various stages of economic development. This is vital given the evidence suggesting that polarisation in reproductive behaviour is more pronounced in Latin America and in other LMICs than it is in HICs (e.g., Lima et al. 2018). Although we are learning more about the past and possible future of differences in cohort fertility by educational level in HICs, the evolution of these trends remains largely unexplored outside of that context. Further research on the topic in LMICs is needed to enable us to broaden our knowledge about the changes in fertility patterns worldwide. 


\section{Acknowledgments}

Most of this research was conducted while Ewa Batyra was a PhD student in the Department of Social Policy, London School Economics and Political Science, and was supported by the UK Economic and Social Research Council Doctoral Studentship (ES/J500070/1). Ewa Batyra also acknowledges support of the University of Pennsylvania (through the National Science Foundation grant no. 1729185 for the Global Family Change Project, PIs: Kohler \& Furstenberg) and Max Planck Institute for Demographic Research (through the Max Planck Society Grant), which hosted her as a postdoctoral fellow while part of this research was conducted. We are also grateful for helpful comments from Peng Li.

\section{References}

Azevedo, J P, M Favara, S E Haddock, L F Lopez-Calva, M Müller, and E Perova. 2012. "Teenage Pregnancy and Opportunities in Latin America and the Caribbean." Washington, DC: World Bank Group.

Berquó, Elza S., and Suzana Cavenaghi. 2005. "Brazilian Fertility Regimes: Profiles of Women below and above Replacement Levels." Paper presented at the International Union for the Scientific Study of Population. Tours, July 18-23, 2005.

—. 2014. "Notas Sobre Os Diferenciais Educacionais e Econômicos Da Fecundidade No Brasil." Revista Brasileira de Estudos de População 31 (2): 471-82.

Berrington, Ann, Juliet Stone, and Éva Beaujouan. 2015. "Educational Differences in Timing and Quantum of Childbearing in Britain: A Study of Cohorts Born 1940-1969." Demographic Research 33 (1): 733-64.

Bohk-Ewald, Christina, Peng Li, and Mikko Myrskylä. 2018. "Forecast Accuracy Hardly Improves with Method Complexity When Completing Cohort Fertility." Proceedings of the National Academy of Sciences of the United States of America 115 (37): 9187-92.

Bongaarts, John, and Griffith Feeney. 1998. "On the Quantum and Tempo of Fertility." Population and Development Review 24 (2): 271-91.

Brass, W. 1975. Methods for Estimating Fertility and Mortality from Limited and Defective Data. Chapel Hill: University of North Carolina Press.

Caetano, André J., and Joseph E. Potter. 2004. "Politics and Female Sterilization in Northeast Brazil." Population and Development Review 30 (1): 79-108.

Carvalho, José Alberto Magno De, and Laura L Rodríguez Wong. 1996. “The Fertility Transition in Brazil: Causes and Consequences." In The Fertility Transition in Latin America, edited by José Miguel Guzmán, Susheela Singh, G Rodriguez, and Eedith A Pantelides, 373-96. Oxford: Clarendon Press.

Castanheira, Helena Cruz, and Hans-Peter Kohler. 2016. "It Is Lower than You Think It Is: Recent Total Fertility Rates in Brazil and Possibly Other Latin American Countries." Paper presented at the Annual Meeting of the Population Association of America, Washington DC., March 30-April 2, 2016.

Cavenaghi, Suzana, and Elza S. Berquó. 2014. "Perfil Socioeconômico e Demográfico Da Fecundidade No Brasil de 2000 a 2010." Paper presented at the VI Congress of the Latin American Population Association, Lima, 12-15 August, 2014. 
Cetorelli, Valeria. 2014. "The Effect on Fertility of the 2003-2011 War in Iraq." Population and Development Review 40 (4): 581-604.

Chackiel, J, and S Schkolnik. 1996. "Latin America: Overwiev of the Fertility Transition, 1950-1990." In The Fertility Transition in Latin America, edited by José Miguel Guzmán, Susheela Singh, G Rodriguez, and Eedith A Pantelides. Oxford: Clarendon Press.

Cho, Lee-Jay, Robert D Retherford, and M Choe. 1986. The Own-Children Method of Fertility Estimation. Honolulu: University of Hawaii Press.

Ellison, Joanne, Erengul Dodd, and Jonathan J. Forster. 2020. "Forecasting of Cohort Fertility under a Hierarchical Bayesian Approach." Journal of the Royal Statistical Society. Series A: Statistics in Society 183 (3): 829-56.

Ferrara, Eliana La, Alberto Chong, and Suzanne Duryea. 2012. "Soap Operas and Fertility: Evidence from Brazil." American Economic Journal: Applied Economics 4 (4): 1-31.

Frejka, Tomas, and Jean Paul Sardon. 2004. Childbearing Trends and Prospects in LowFertility Countries. A Cohort Analysis. Dordrecht, Boston, London: Kluwer Academic Publishers.

Goldani, Ana Maria. 2002. "What Will Happen to Brazilian Fertility?" Population Bulleting of the United Nations: Completing the Fertility Transition. Population Bulletin of the United Nations: Completing the Fertility Transition. Special Issue Nos. 48/49. New York: United Nations.

Goldstein, Joshua, Tomas Sobotka, and Aiva Jasilioniene. 2009. "The End of ' Lowest-Low' Fertility?" Population and Development Review 35 (4): 663-99.

Hellstrand, Julia, Jessica Nisén, Vitor Miranda, Peter Fallesen, Lars Dommermuth, and Mikko Myrskylä. 2020. "Not Just Later, but Fewer: Novel Trends in Cohort Fertility in the Nordic Countries." MPIDR Working Paper WP 2020-007.

Hellstrand, Julia, Jessica Nisén, and Mikko Myrskylä. 2020. “All-Time Low Period Fertility in Finland: Demographic Drivers, Tempo Effects, and Cohort Implications." Population Studies 74 (3): 315-29.

IBGE. 2008. "Metodologia Das Estimativas Das Populações Residentes Nos Municípios Brasileiros." Rio de Janeiro: IBGE.

—. 2010a. "Censo Demografico 2010: Fecundidade e Mortalidade Infantil." Instituto Brasileiro de Geografia e Estatistica - IBGE. Rio de Janeiro: IBGE.

_. 2010b. "Indicators and Basic Data, Brazil, 2010.” Rio de Janeiro: IBGE. 2010. http://www.datasus.gov.br/idb2010.

Jalovaara, Marika, Gerda Neyer, Gunnar Andersson, Johan Dahlberg, Lars Dommermuth, Peter Fallesen, and Trude Lappegård. 2019. "Education, Gender, and Cohort Fertility in the Nordic Countries." European Journal of Population 35 (3): 563-86.

Kohler, Hans-Peter, Francesco C Billari, and José Antonio Ortega. 2002. "The Emergence of Lowest-Low Fertility in Europe During the 1990s." Population and Development Review 28 (4): 641-80.

Leone, Tiziana. 2002. "Fertility and Union Dynamics in Brazil." PhD Thesis, University of Southampton.

Lima, Everton E. C. 2013. "Age-Specific Fertility Rates: Estimations Based on Brazilian Census Data." Human Fertility Collection. Rostock: Max Planck Institute for Demographic Research. Vienna: Vienna Institute of Demography. 2013.

Lima, Everton E. C., Krystof Zeman, Tomas Sobotka, Mathias Nathan, and Ruben Castro. 2018. "The Emergence of Bimodal Fertility Profiles in Latin America." Population and Development Review 44 (4): 723-43.

Lwendo, M, and M Levin. 2017. "New Own Children: Methodology and Results from Africa DHS and Census Data (IPUMS)." Methodology presened at the Conference Children, 
Mothers and Measuring Fertility: New Perspectives on the Own Child Method, University of Cambridge. September 18-20, 2017.

Marteleto, L.J., M. Dondero, and A. Koepp. 2021. "Double Exposure to Novel Infectious

Diseases: ZIKV, Covid-19 and the Context of Fertility." Paper presented at the Annual Meeting of the Population Association of America, April 4-8, 2021.

Marteleto, Leticia, and Molly Dondero. 2013. "Maternal Age at First Birth and Adolescent Education in Brazil.” Demographic Research 28 (28): 793-820.

Martine, George. 1996. "Brazil's Fertility Decline, 1965-95: A Fresh Look at Key Factors." Population and Development Review 22 (1): 47-75.

Martins, Paulo Henrique Viegas. 2016. "Mudanças Recentes Na Fecundidade Adolescente No Brasil: A Associação Com a Escolaridade Continua a Mesma?” Master's Thesis, Universidade Federal de Minas Gerais.

Minnesota Population Center. 2017. "Minnesota Population Center. Integrated Public Use Microdata Series, International: Version 6.5 [Brazil 1980,1991,2000,2010]."

Minneapolis: University of Minnesota. Minneapolis: University of Minnesota. 2017.

Miranda-Ribeiro, Adriana De, and Ricardo Alexandrino Garcia. 2013. "Transition or Transitions? Analyzing the Fertility Decline in Brazil in the Light of Educational Levels." Revista Latinoamericana de Población 7 (13): 91-106.

Miranda-Ribeiro, Adriana De, Paula De Miranda-Ribeiro, and Eduardo L. G. Rios-Neto. 2017. "Brazilian Cohort Fertility by Education and Color/ Race: Trends and Future Scenarios for Projections." Paper presented at the International Union for Scientific Study of Population, Cape Town, October 29- November 4, 2017.

Miranda-Ribeiro, Adriana De, Eduardo L. G. Rios-Neto, and José Antonio Ortega. 2008. "Declínio Da Fecundidade No Brasil e México e o Nível de Reposição: Efeitos Tempo, Parturição e Quantum." In Población y Salud Sexual y Reproductiva En América Latina, edited by Laura Rodríguez Wong. Rio de Janeiro: ALAP.

Myrskylä, Mikko, Joshua R. Goldstein, and Yen Hsin Alice Cheng. 2013. "New Cohort Fertility Forecasts for the Developed World: Rises, Falls, and Reversals." Population and Development Review 39 (1): 31-56.

Nisén, Jessica, Sebastian Klüsener, Johan Dahlberg, Lars Dommermuth, Aiva Jasilioniene, Michaela Kreyenfeld, Trude Lappegård, et al. 2021. "Educational Differences in Cohort Fertility Across Sub-National Regions in Europe." European Journal of Population 37 (1): 263-95.

Potter, Joseph E. 1999. "The Persistence of Outmoded Contraceptive Regimes: The Cases of Mexico and Brazil.” Population and Development Review 25 (4): 703-39.

Retherford, Robert D, Aphichat Chamratrithirong, and Anuri Wanglee. 1980. "The Impact of Alternative Mortality Assumptions on Own-Children Estimates of Fertility for Thailand." Asian and Pacific Census Forum 6 (3): 5-8.

Retherford, Robert D, C Pejaranonda, L Cho, A Chamratrithirong, and F Arnold. 1979. "Own-Children Estimates of Fertility for Thailand Based on the 1970 Census." Papers of the East-West Population Institute No. 63, no. 63.

Rindfuss, Ronald R., and James A. Sweet. 1977. Postwar Fertility Trends and Differentials in the United States. Amsterdam: Elsevier Science.

Rios-Neto, Eduardo L. G., and Adriana De Miranda-Ribeiro. 2015. "Fertility Decline in Brazil: Tempo, Quantum and Parity Composition Effects." Paper presented at the Population Association of America Annual Meeting, San Diego, April 30 - May 2, 2015.

Rios-Neto, Eduardo L. G., Adriana De Miranda-Ribeiro, and Paula De Miranda-Ribeiro. 2018. "Fertility Differentials by Education in Brazil: From the Conclusion of Fertility to the Onset of Postponement Transition." Population and Development Review 44 (3): 489-517. 
Rios-Neto, Eduardo L. G., Paula De Miranda-Ribeiro, and Joseph E. Potter. 1998. "I Saw It on TV: Television and Demographic Change in Brazil." Paper Presented at the Workshop on the Social Dynamics of Fertility Change in Developing Countries. National Academy of Sciences, Washington, DC.

Rodríguez Vignoli, Jorge. 2013. "High Adolecent Fertility in the Context of Declining Fertility in Latin America." Expert Paper No. 2013/14. New York: United Nations.

_. 2014. "Fecundidad Adolescente En América Latina: Una Actualización." In Comportamiento Reproductivo y Fecundidad En Latin America: Una Agenda Inconclusa, edited by Suzana Cavenaghi and Wanda Cabella. Rio de Janeiro: ALAP.

—. 2017. "Deseabilidad y Planificación de La Fecundidad Adolescente En América Latina y El Caribe: Tendencias y Patrones Emergentes." Notas de Población 104: 11944.

Rosero-Bixby, Luis, Teresa Castro-Martín, and Teresa Martín-García. 2009. "Is Latin America Starting to Retreat from Early and Universal Childbearing?” Demographic Research 20 (9): 169-94.

Scalone, F, and M Dribe. 2017. "Testing Child-Woman Ratios and the Own-Children Method on the 1900 Sweden Census: Examples of Indirect Fertility Estaimtes by Socioeonomic Status in a Historical Population." Paper presened at the Conference Children, Mothers and Measuring Fertility: New Perspectives on the Own Child Method, University of Cambridge. September 18-20, 2017.

Schmertmann, Carl P., Emilio Zagheni, Joshua R. Goldstein, and Mikko Myrskylä. 2014. "Bayesian Forecasting of Cohort Fertility." Journal of the American Statistical Association 109 (506): 500-513.

UNDESA. 1982. "Model Life Tables for Developing Countries.” Department fo International Economic and Social Affairs, Population Studies, no.77. Untied Nations: New York.

United Nations. 2013. "MORTPAK for Windows, Version 4.3. New York: United Nations." New York: United Nations.

Verona, Ana Paula. 2018. "The End of the Rejuvenation of the Fertility Schedule in Brazil: Evidence from Changes in Contraception Use and Reproductive Preferences among Adolescents and Young Women." Population Review 57 (1): 20-27.

World Bank. 2020. "The World Bank Data.” Washington, DC: World Bank Group. 2020. https://data.worldbank.org/indicator/SP.DYN.LE00.IN.

Yoo, Sam Hyun. 2014. "Educational Differentials in Cohort Fertility during the Fertility Transition in South Korea." Demographic Research 30 (53): 1463-94. 


\section{Tables}

Tab.1 IPUMS census sample sizes and the number of women aged 15-64 in each sample; period for which ASFRs are reconstructed from each census, Brazil

\begin{tabular}{|l|l|l|l|}
\hline $\begin{array}{l}\text { Census } \\
\text { date }\end{array}$ & $\begin{array}{l}\text { IPUMS census sample } \\
\text { size }(\% \text { of the total } \\
\text { population) }\end{array}$ & $\begin{array}{l}\text { Number of women } \\
\text { aged 15-64 }\end{array}$ & $\begin{array}{l}\text { Time period for which } \\
\text { ASFRs are reconstructed }\end{array}$ \\
\hline 2010 & $9,693,058(5.0 \%)$ & $3,292,648$ & $1996-2010$ \\
\hline 2000 & $10,136,022(6.0 \%)$ & $3,275,351$ & $1986-2000$ \\
\hline 1991 & $8,522,740(5.8 \%)$ & $2,579,371$ & $1977-1991$ \\
\hline 1980 & $5,870,467(5.0 \%)$ & $1,738,469$ & $1966-1980$ \\
\hline
\end{tabular}

Source: Authors' calculations from the 1980, 1991, 2000, and 2010 IPUMS censuses. 
Tab.2 Educational differences in the cohort fertility rate (Educ. Diff $=$ CTFR low educated CTFR high educated) calculated based on the education-specific observed CTFRs (1960-1964) and forecasted CTFRs (1970-1984) using four methods, total population CTFR in the parentheses, Brazil

\begin{tabular}{|l|l|l|l|l|}
\hline Cohort & $\begin{array}{l}\text { Educ. Diff. } \\
\text { (5-year extrap.) }\end{array}$ & $\begin{array}{l}\text { Educ. Diff. } \\
\text { (Bayes. 2014) }\end{array}$ & $\begin{array}{l}\text { Educ. Diff. } \\
\text { (Bayes. 2020) }\end{array}$ & $\begin{array}{l}\text { Educ. Diff. } \\
\text { (Freeze rate) }\end{array}$ \\
\hline 1960 & $1.41(3.08)$ & $1.41(3.08)$ & $1.41(3.08)$ & $1.41(3.08)$ \\
\hline 1964 & $1.21(2.79)$ & $1.21(2.79)$ & $1.21(2.79)$ & $1.21(2.79)$ \\
\hline 1970 & $1.16(2.53)$ & $1.16(2.53)$ & $1.16(2.53)$ & $1.16(2.53)$ \\
\hline 1974 & $1.03(2.30)$ & $1.05(2.31)$ & $1.05(2.31)$ & $1.05(2.30)$ \\
\hline 1980 & $0.86(2.14)$ & $0.91(2.14)$ & $0.94(2.14)$ & $0.94(2.13)$ \\
\hline 1984 & $0.73(1.92)$ & $0.81(1.93)$ & $0.85(1.92)$ & $0.85(1.91)$ \\
\hline
\end{tabular}

Source: Authors' calculations from the 1980, 1991, 2000, and 2010 IPUMS censuses. 


\section{Figures}

Fig. 1 Selected age-specific fertility rates trends (age 15, 20, 30, 35), 1980, 1991, 2000, and 2010 censuses for the 1966-2010 period, raw (left panel) and combined (right panel), total population, Brazil

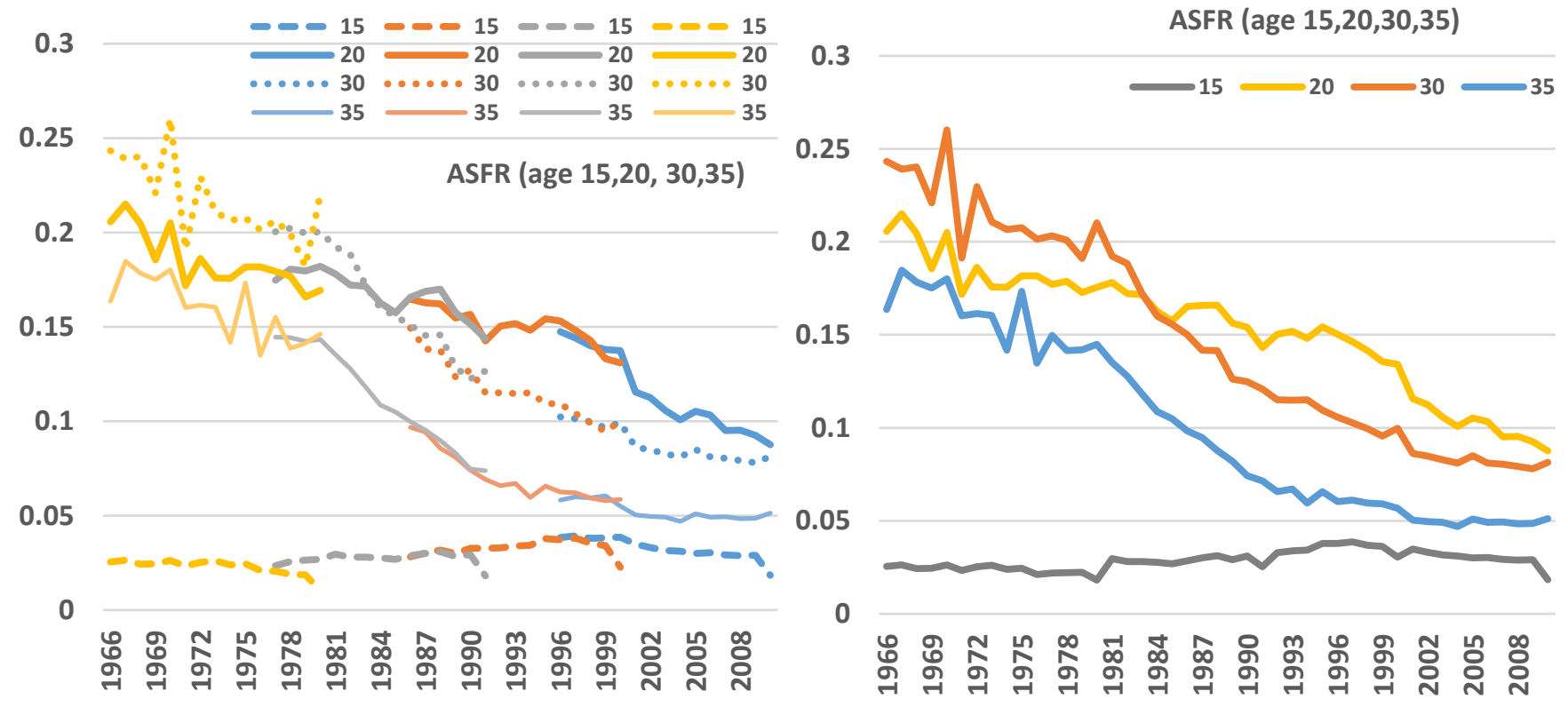

Source: Authors' calculations from the 1980, 1991, 2000 and 2010 IPUMS censuses, own children method estimates. 
Fig. 2 Cohort total fertility rate (CTFR) (bottom x-axis) observed (1964-1966) and forecasted (1967-1984), with 95\% CIs (Bayesian methods). Period total fertility rate (PTFR), 1966-2010 (top x-axis). Total population, Brazil.

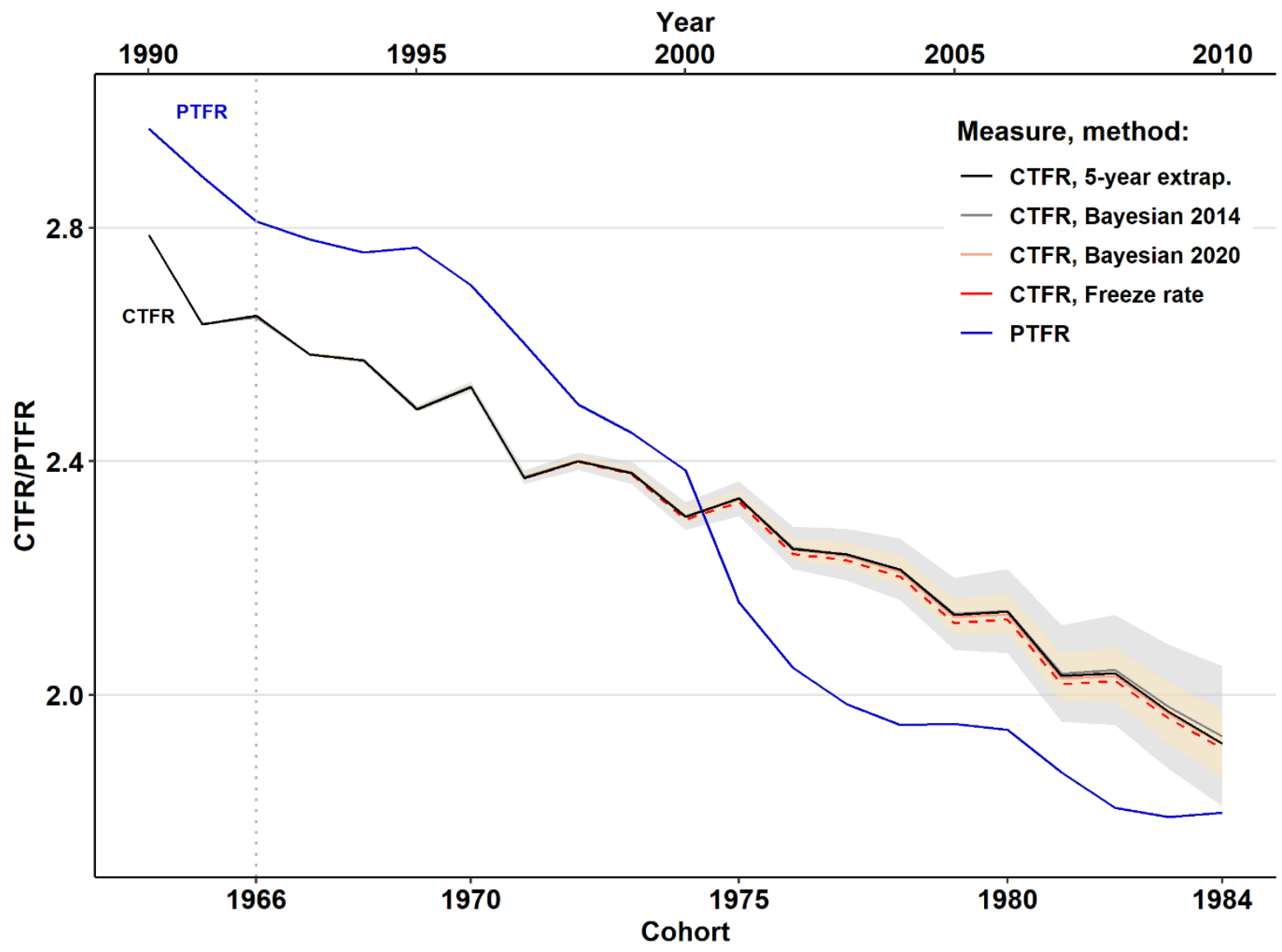

Source: Authors' calculations from the 1980, 1991, 2000, and 2010 IPUMS censuses. 
Fig.3 Cohort age-specific fertility schedules observed (solid) and forecasted rates from the 2014 Bayesian model (means of the CTFR forecast dashed, 95\% CIs - dotted). Total population (total, left panel) and by educational level (low and high, middle and right panels), selected cohorts, Brazil
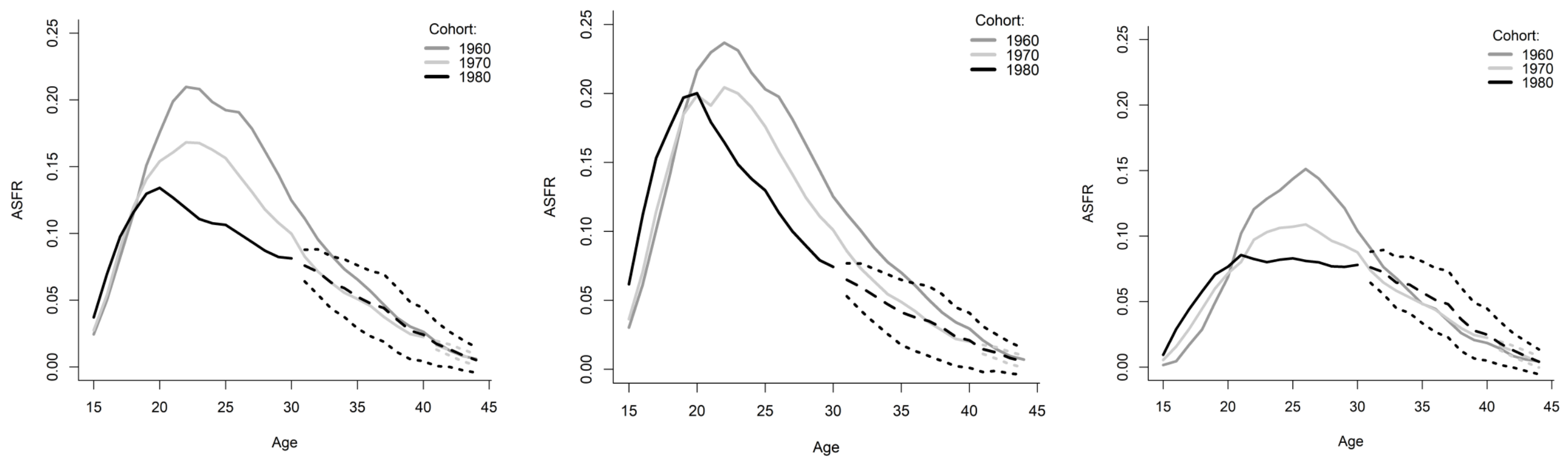

Source: Authors' calculations from the 1980, 1991, 2000, and 2010 IPUMS censuses. 
Fig.4 Cohort total fertility rate (CTFR) (bottom x-axis) observed (1964-1966) and forecasted (1967-1984), with 95\% CIs (Bayesian methods). Period total fertility rate (PTFR) 1966-2010 (top x-axis). By educational level, Brazil

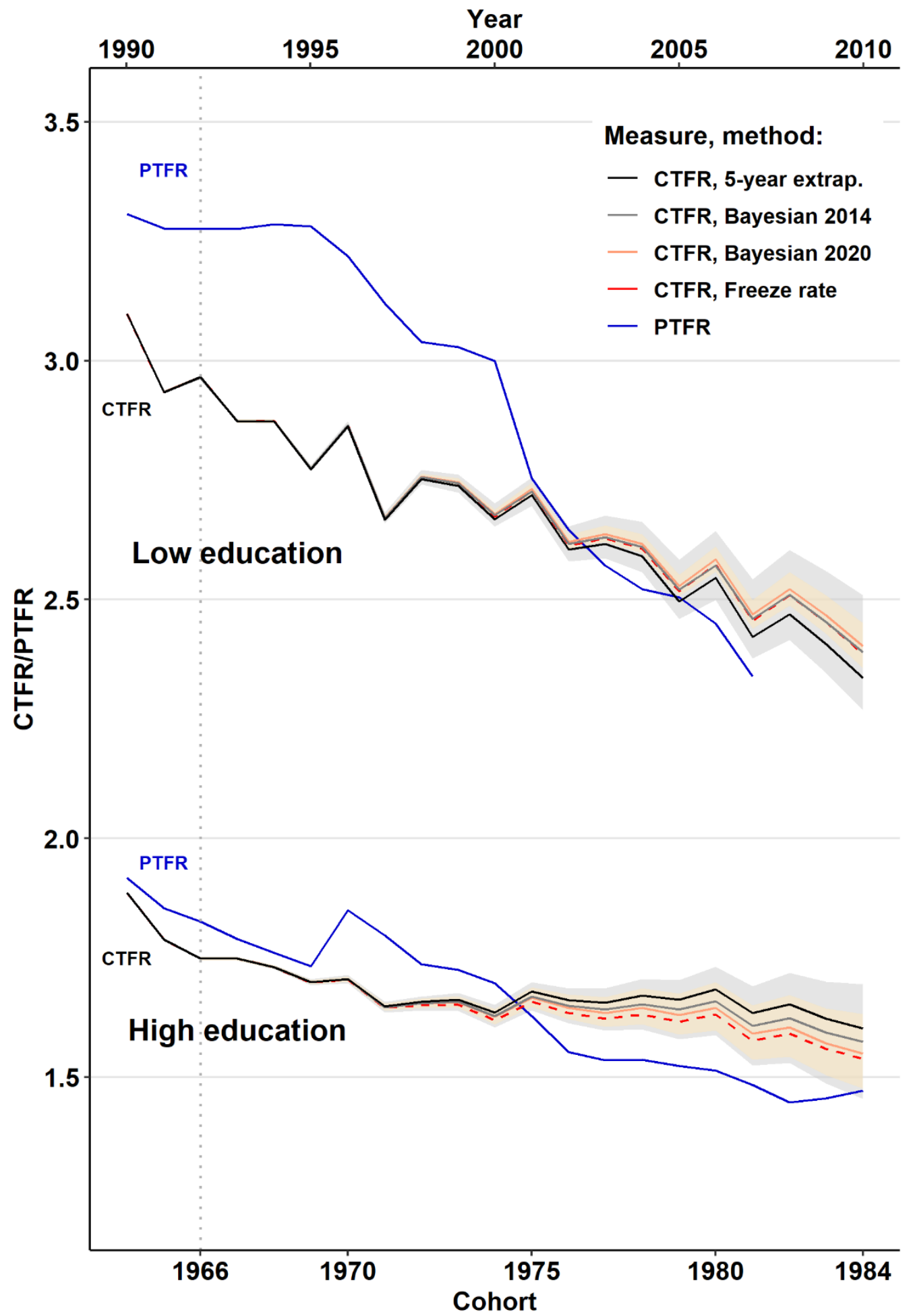

Note: The PTFR estimates for women with low levels of education are truncated starting in the year 2007 for the reasons explained in the data section.

Source: Authors' calculations from the 1980, 1991, 2000, and 2010 IPUMS censuses. 


\section{Online Appendices}

\section{Appendix 1: Estimation of the time series of ASFRs for educational groups}

When the OCM is used to estimate fertility trends by socio-economic characteristics, the method is based on the assumption that a value of a given characteristic at the time of the census applies to the time period for which the rates are reconstructed. For this study, the potential problem of incomplete educational trajectories, as explained in the data section, relates to women in the 15-19 age group. This is because entrance into secondary school, which is used in this study to determine whether a given woman belongs to the low or the high educational category, typically occurs before age 20 . This issue is known to result in the underestimation of fertility rates for the youngest age groups in the years just before the census date among women with the low levels of schooling (Rindfuss and Sweet 1977). Figure S1 shows that this is the case for Brazil as well. For women with low levels of education, there is evidence of the underestimation of the fertility rate at age 15 for around three years prior to the census. This problem is diminished the higher the age group that is considered, and although it is still visible at age 20, it disappears for the older ages (for example, at age 25). To minimise the bias resulting from this problem, we use an approach suggested in previous research (Rindfuss and Sweet 1977). When combining the estimates from the two consecutive censuses, we exclude the estimates three years before each census for the ages from 15 to 20 . The two remaining overlapping years from the two censuses are combined using the same procedure as for the total population. This results in the truncation of the rates in year 2007 for the 15-20 age group. Consequently, for the lower educated women, it is not possible to calculate the total fertility rate beyond that time point. However, the cohort analysis is not affected, since these rates correspond to the fertility experiences of women born after 1985 .

The extent of the possible bias resulting from this problem is less clear for women who had already completed some secondary school. The retrospective estimates close to the census date are based on the subset of women who already entered that educational category. If these women are representative of those who will eventually end up in that group, the bias should not be severe. However, the extent of it cannot be assessed. Figure S2 shows that the problem of the sharp decline in fertility rates at younger ages is not observed for the higher educated women. However, overlap of the estimates below age 25 is, in general, less consistent for this educational group. The most pronounced differences are found for the estimates obtained from 
the 2000 and 2010 censuses. Beyond age 25, the level of agreement in the rates is very good across all of the censuses (not shown). The lower level of agreement between the estimates for this educational group should be acknowledged and kept in mind when examining the results of this study. It should, however, be emphasised that the level of the disagreement in the rates from consecutive censuses for this educational group does not exceed the discrepancies typically found when using the OCM estimation, as has been shown in, for example, Rindfuss and Sweet (1977). We combine the estimates from censuses for the overlapping time periods for this educational group in a manner similar to that used for the total population, at all ages.

Overall, the PTFR estimates calculated based on the reconstructed ASFRs align with the existing estimates of the PTFR for women with 9+ years of schooling (Rios-Neto et al. 2018) (see Appendix 3). This gives us confidence that the results of our approach result in aggregated fertility trends that are plausible. We did not identify studies that estimated the PTFR for women with 0-9 years of schooling. Usually, the rates are estimated for more detailed educational categories, e.g., 0-3 and 4-8 years. 
Fig. S1 Selected age-specific fertility rates trends (age 15, 20, 25) from the 1980, 1991, 2000, and 2010 censuses for the 1966-2010 period, raw (left panel) and combined (right panel), low educational level, Brazil

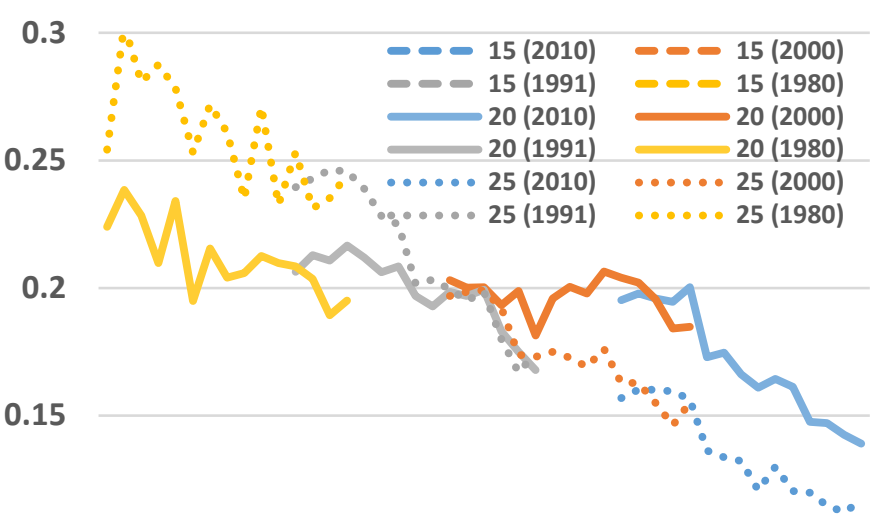

0.1

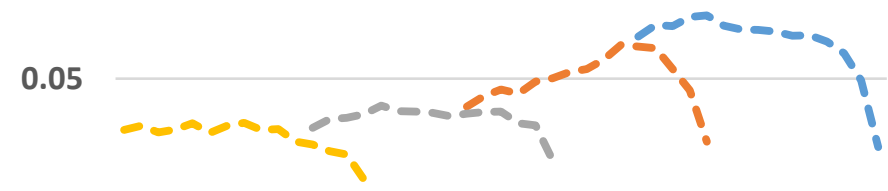

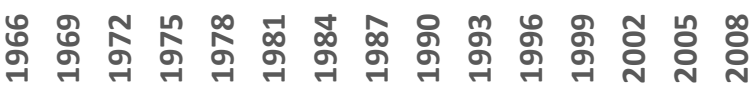

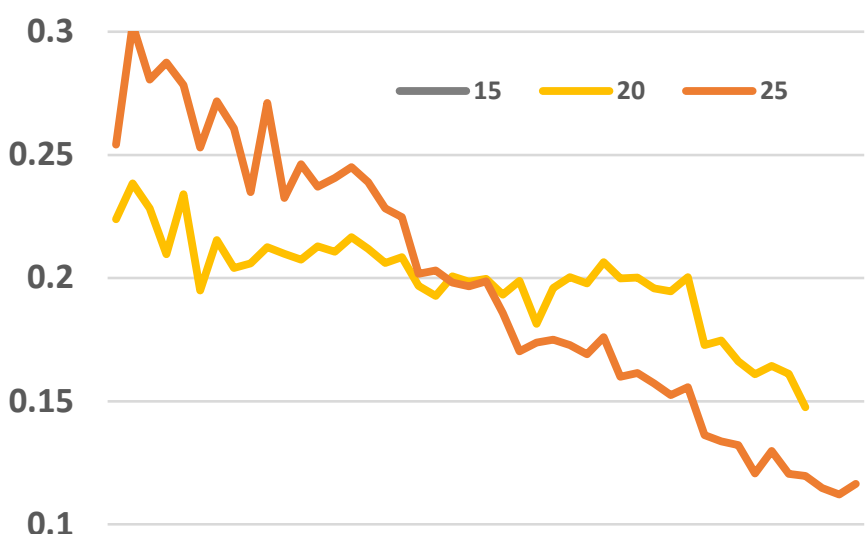

0.05

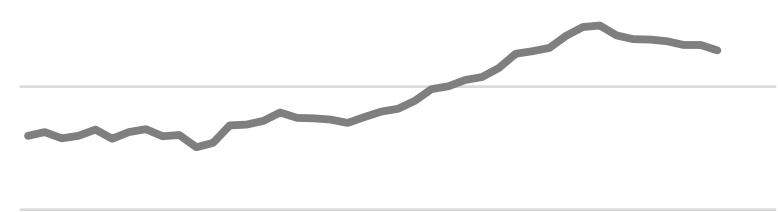

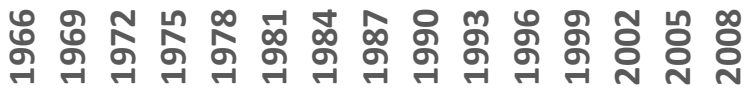

Source: Authors' calculations from the 1980, 1991, 2000, and 2010 IPUMS censuses, own children method estimates.

Fig. S2 Selected age-specific fertility rates trends (age 15, 20, 25) from the 1980, 1991, 2000, and 2010 censuses for the 1966-2010 period, raw (left panel) and combined (right panel), high educational level, Brazil
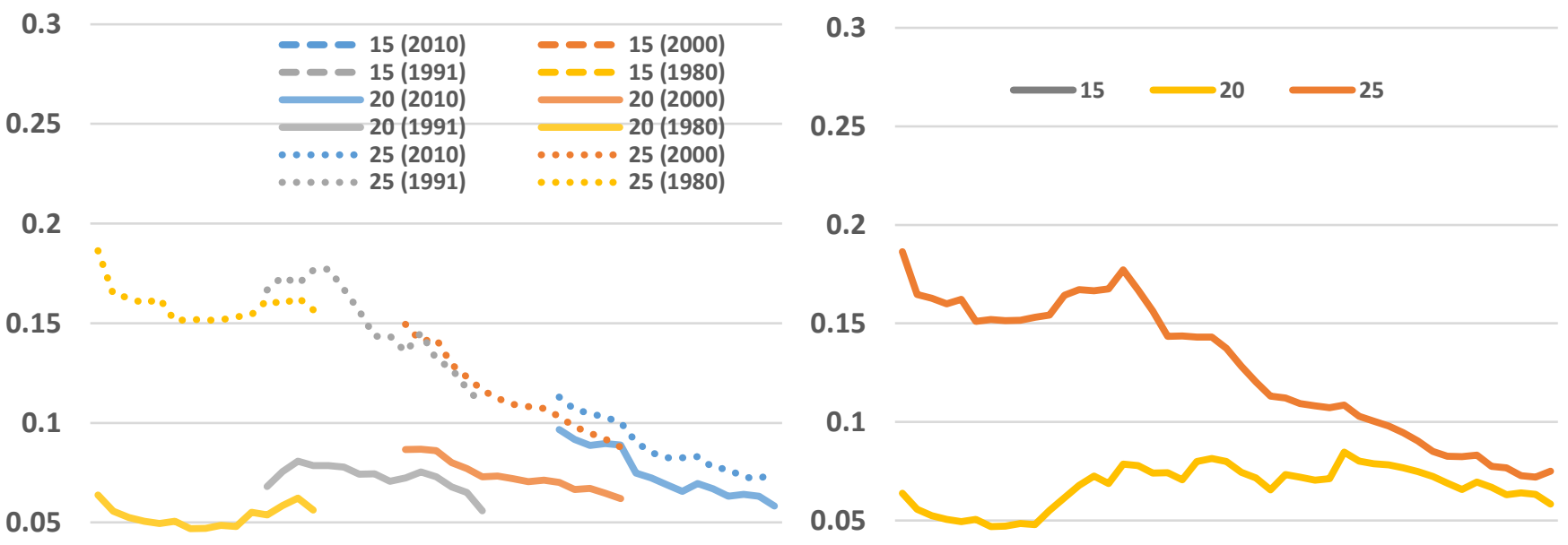

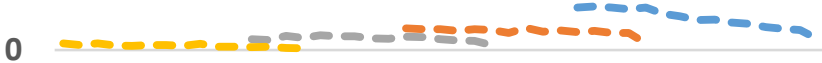

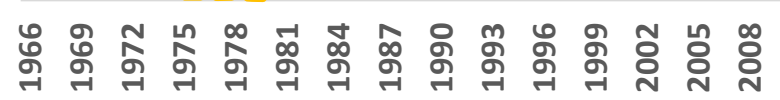

0

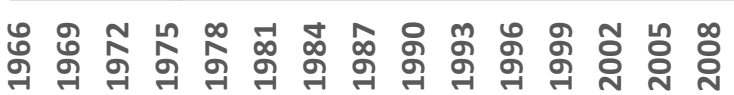

Source: Authors' calculations from the 1980, 1991, 2000, and 2010 IPUMS censuses, own children method estimates. 


\section{Appendix 2: Sensitivity analysis of the cohort fertility trends to mortality assumptions}

The own children method (OCM) relies on the estimates of mortality for the reverse-survival procedure. Since detailed life tables or estimates of life expectancy at birth are not available for Brazil for subpopulations for the period covered by this analysis, in this study, we assumed that the mortality pattern is the same among all individuals. As a sensitivity analysis, we examined how the results would differ if differentiated patterns of mortality between educational groups were assumed.

In order to obtain the estimates of the possible differences in mortality by level of education, we used the Brass method of estimating child mortality from census data (Brass 1975). From data about the number of children ever born and surviving by the age of women from each census, we estimated child mortality levels for 15 years preceding each census. Subsequently, we matched the child mortality estimates with the Coale-Demeny model life tables using the MORTPAK programme (United Nations 2013). This procedure permits us to obtain the complete life tables for all ages for the 1966-2010 period. This method has been previously suggested as a way of approximating the mortality patterns using census data when the estimates from external sources are not available (Cho et al. 1986).

These results suggest that, as expected, life expectancy at birth for more educated women is higher than that for less educated women. The differences between the educational groups range from 11 to two years, depending on the period. We use these education-specific estimates of life expectancy to explore whether accounting for the differences in mortality by educational level in the OCM estimation could bias the main results of this study. We find that the differences in our results are very small, and in the expected direction. As we found in previous studies (Retherford et al. 1980), the use of the constant mortality pattern underestimates the level of fertility among women with low levels of education and overestimates fertility among women with high levels of education. Nevertheless, our conclusions regarding the trends in CTFR, both observed and forecasted, are not sensitive to whether we use education-specific life expectancy or life expectancy for the total population when estimating the ASFRs for the educational groups. This is consistent with the studies that show that the OCM is unlikely to be sensitive to mortality assumptions (Retherford et al. 1980; Cho et al. 1986; Scalone and Dribe 2017). 


\section{Appendix 3: Reconstructed trends in period total fertility rates and cohort total fertility rates}

Fig. S3 Reconstructed trends in period total fertility rates (PTFRs) (1966-2010) and cohort total fertility rates (CTFR) (1951-1966), for total population and by educational level. Estimates of PTFRs for each census by the Brazilian Statistical Office - All IBGE (IBGE 2010a) and of PTFRs for women with 9+ years of schooling from Rios-Neto et al. (2018) - RS_2018
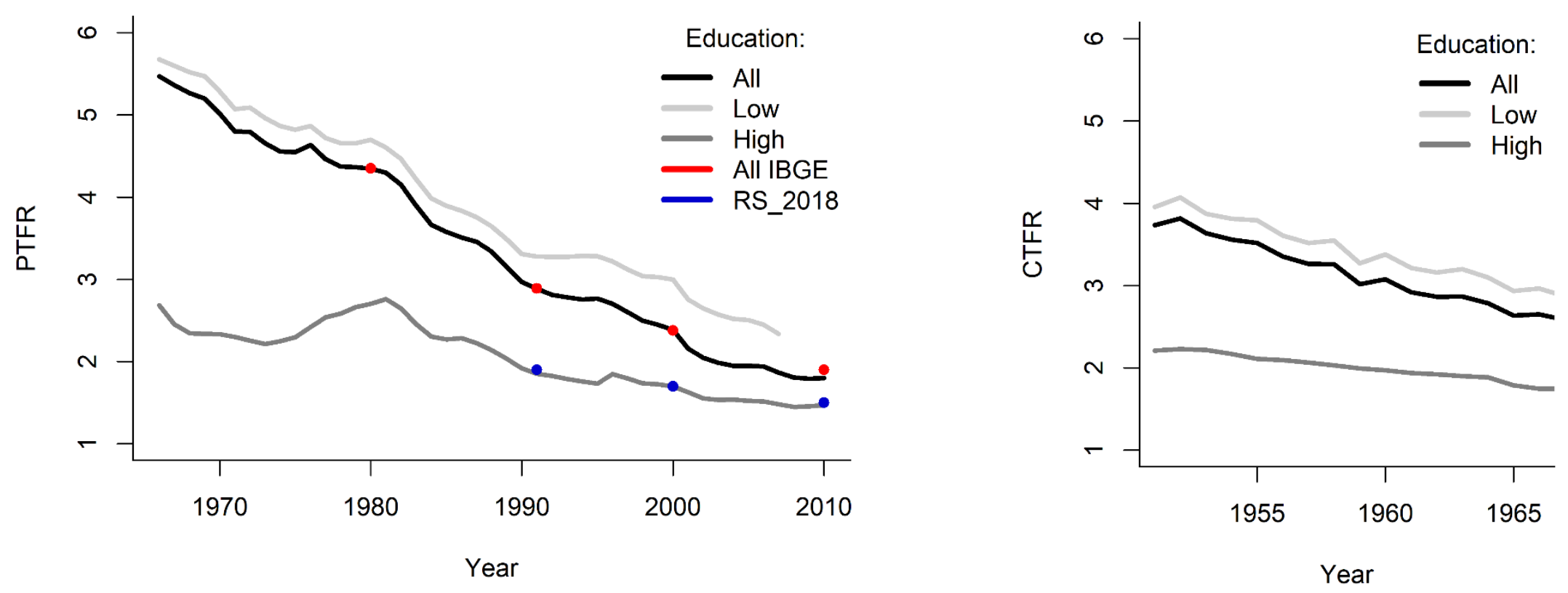

Note: The PTFR estimates for women with low levels of education are truncated starting in the year 2007 for the reasons explained in the data section. Source: Authors' calculations from 1980, 1991, 2000, and 2010 IPUMS censuses. 